\title{
A QUESTÃO DA DETERMINAÇÃO DO PROCESSO SAƯDE-DOENÇA
}

\author{
Cilene Aparecida Costardi Ide* \\ Eliane Corrêa Chaves*
}

IDE, C.A.C. \& CHAVES, E.C. A questão da determinação do processo saúde-doença. Rev. Esc. Enf. USP, São Paulo, 24(1):163-167, abr. 1990.

Nesse trabalho são identificadas as diferentes possibilidades de compreensão do contexto de saúde-doença.

UNITERMOS: Saúde e doenca. Classe social.

A análise das condições de saúde-doença de uma população pode ser realizada a partir de diferentes referenciais metodológicos. A especificidade de cada um deles decorreria do conceito atribuído a esse processo, da identificação e relação estabelecidas entre os fatores considerados intervenientes ou determiriantes, levando em conta ou não as caracterís ticas peculiares da vida. Decorreria, ainda, da articulação entre as diversas possibilidades de compreender e intervir sobre a realidade, delineando alternativas de desempenho profissionais compativeis a cada concepção.

Nesse contexto, existiria uma gama de posições analíticas divergentes que se polarizam, tendo, num extremo, uma visão ideal, baseada na formulação de normas para saúde e desvio, como resultantes da relação do homem com o meio natural (interno e externo), contrapondo-se a uma proposta sociológica-descritiva do processo, segundo a qual a sociedade é quem determina e reconhece o estado de saúde dos seus membros.

A dimensão isolada do processo saúde-doença, enquanto resposta orgânica às condições naturais, compreende teorias que se sucederam na tentativa de elucidar essa problemática, a partir da valorização de expressões externas, sobrenaturais, biológicas ou ecológicas enquanto fatores que, de forma isolada, agiriam sobre um homem homogêneo, provo-cando desequilíbrios considerados como anormalidades. Nesse referencial identifica-se, preliminarmente, a teoria unicausal que reconhece uma origem única e fundamental para a produção do efeito doença, sempre colocada fora do organismo doente. Assim, ao meio natural e por força do destino caberia a origem dos males, numa concepção prevalente desde as primórdios da humanidade. A transição dessa concepção para uma com respaldo científico surge atrelada à decomposição da ordem feudal

\footnotetext{
* Enfermeiras. Professoras Assistentes do Departamento de Enfermagem Médico-Cirúrgica dia Escola de Enfermagem da USP.
} 
e o desencadeamento do modelo capitalista. Uma evolução efetiva sơ teria ocorrido quando as relações de produção assumiram feição adequada à implantação do capitalismo industrial, suscitando o aparecimento no mercado de trabalho de uma oferia suficiente de pessoas que precisariam estar aptas a movimentarem as novas máquinas em troca de remuneração.

Esse processo evolutivo foi lento e gradativo, atingindo o apogeu somente nos meados do século 19. Nessa fase, o imenso desenvolvimento) das ciências físico-químicas e naturais, incluindo as descobertas microbiológicas, deslocariam para o microorganismo a causalidade da doença, superando as explicações naturais ${ }^{2,6}$.

Entretanto a teoria da unicausalidade perde a possibilidade de responder às questões que emergiam da nova configuração econômico-social determinante de um quaöro nosológico complexo, caracterizado pela perpetuação das doenças transmissiveis e pelo desenvolvimento das afecções crônico-degenerativas, comportamentais e ocupacionais. A complexidade dessa situação potencializaria a necessidade de um novo modelo explicativo. A fragilidade do paradigma vigente se evidenciava pela sua incapacidade, tanto de gerar novos conhecimentos que possibilitem a compreensão dos principais problemas de saúde emergentes, como também pela crise da prática frente à deteriorização dos pádrões de vida da maioria e suas consequiências na dimensão individual de saúde-doença.

Face a esse vazio conceitual começa a desenvolver-se, a partir dos meados do século 20, a teoria da multicausalidade da doença. Essa concepção estaria apta a identificar um conjunto de fatores capazes de produzir alterações físicas passiveis de correção a partir de medidas coletivas de intervenção na cadeia causal, sem aprofundar a questão da trama de processos presentes na origem dessa problemática. Essa concepção teria, no modelo da tríade ecológica de LEAVELL \& CLARK ${ }^{5}$, uma fase mais elaborada e dinâmica do processo saúde-doença. Nesta teoria, o equilíbrio da saúde dependeria da interação entre o meio ambiente (físico, social, econômico e biológico), diferentes agentes (biológicos, nutrientes, químicos e mecânicos) e o hospedeiro humano (considerado a partir de características etárias, raciais, sexuais, de hábitos, costumes, fatores genéticos, personalidade e mecanismos de defesa). A intervenção nesse processo abrangeria medidas voltadas à prevenção primária, incluindo a promoção da saúde e proteção específica; à secundária, a partir tanto do diagnástico precoce e pronto atendimento quanto da limitação da invalidez, além da prevenção terciária, agregando as medidas de reabilitação ao contexto das práticas assistenciais.

Essa teoria teria uma dimensão inovadora ao ampliar a visão de conjunto dos diferentes episódios mórbidos, possibilitando, ainda, a organização dos conhecimentos e recursos disponiveis no setor saúde, no sentido de prevenir a ocorrência e interromper o evoluir. Sob esse referencial estariam abolidos os limites entre as açōes preventivas e curativas, que comporiam, agora, um elenco de medidas articuladas.

Contudo, teria uma dimensão conservadora na medida em que perpetuaria uma visão limitada e distorcida da realidade, minimizando a 
interdependência entre os diferentes ríscos de adoecer ou manter a saúde e as expressões de modos de produção específicos. Pode-se perceber, portanto, que apesar do meio ambiente abranger todas as coisas exceto o homem, tanto as questões de determinação social do processo saúdedoença quanto a especificidade do hospedeiro, a partir da sua inserção no mundo do trabalho, não são considerados. Partindo de uma concepção tradicional, tanto da doença como das suas causas, supõe-se que o social atue como qualquer outro fator. Apesar de superar o conceito médicoclínico inerente ao modelo unicausal, que entende a doença como um processo biológico ciesencadeado pela interação indivíduo-agente, a multicausalidade, enquanto conceito ecológico, também considera a doença como resultado do desequilibrio na interação indivíduo e ambiente, ainda que conceitualmente ampliado 4 .

Refutando essa concepção, AROUCA ${ }^{1}$ redimensiona os horizontes do social, enquanto sintese de inúmeros fatores a determinar o estado de saúde da população, considerando como meio-ambiente todos os aspectos de um contexto biótico e abiótico, enfatizando a influência daqueles ligados à esfera sócio-econômica (PIB, produção, renda), à educaçãoalfabetização, como também à infra-estrutura de saneamento. Tais considerações são suficientes para refutar qualquer visão limitada desse contexto, justificanỏo, por isso, a opção por outra linha explicativa.

A análise sociológica dessa problemática, alternativa mais ampla e complexa que o modelo biológico, implicaria na identificação dos fatores sociais que determinam o contexto saúde-doença, extrapolando os limites da visão biológica, e na explicitação da articulação entre ambos. A saúde, nesta vertente, resultaria da relação entre um homem, historicamente localizado, com uma função específica no sistema de produção, e a sua inserção num meio natural e social, que molda sua atitude face aos sinais de alterações que lhe são dados perceber. A natureza social da doença não se verificaria no caso clínico, mas na especificidade do processo de adoecer e morrer dos diferentes grupos humanos, ou seja, na análise das condições coletivas de vida. Essa relação entre o processo de saúde-doença coletiva e o indivíduo fica evidente na medida em que o primeiro determina as condições básicas sobre os quais se desenvolvem as variações individuais 4 .

Sob esse prisma, o conceito de saúde se amplia enquanto "resultante ảas condições de alimentação, habitação, educação, renda, meio ambiente, trabalho, transporte, emprego, lazer, liberdade, acesso e posse da terra e acesso a serviços de saúde. $\mathrm{E}$, assim, antes de tudo, o resultado das formas de organização social da produção, as quais podem gerar grandes desigualdades nos níveis de vida" ${ }^{3}$, caracterizando um novo referencial de prática assistencial e de investigação epidemiológica.

Assim sendo, a compreensão desse contexto, em suas diferentes manifestações, a partir da categorização convencional por variáveis biológicas, retrataria uma visão reducionista dessa problemática na medida em que a abrangência do processo saúde-doença extrapola os limites que vinculam a sua existência às características individuais (sexo, idade, ra- 
ça, dentre outras) ou ecológicas, inserindo-se no âmbito da organização social.

Entretanto, explicitados os pressupostos, faz-se necessário caracterizar o processo epidemiológico dos diferentes grupos sociais, apesar das dificuldades em se utilizar as categorizações existentes como indicadores passiveis de refletir a integração e dinâmica do contexto saúdedoença. Essas limitações decorreriam, preliminarmente, das distorções implícitas nos dados oficiais disponíveis, em decorrência dos sub-registros ou da inadequação do tratamento estatístico utilizado que, privilegiando médias e variáveis biológicas, diluiria e distorceria realidades distintas de vida. Além disso, a utilização de indicadores que expressam tanto variações de caráter individual, quanto aspectos isolados dos perfis de reprodução social, permitiria apenas "uma observação mutilada e externa dos processos que determinam o estado de saúde-doença" 2 .

Outro fator limitante refere-se ao pioneirismo, no campo da investigação epidemiológica, de estudos que façam uso integral e sistematizado de categorias, variáveis e indicadores condizentes com uma análise abrangente da estrutura e reprodução social, sendo, portanto, ainda limitados os recursos bibliográficos disponiveis para fundamentar o perfi] do processo saúde-doença conforme esta metodologia.

Para BREILH \& GRANDA 2 , uma das categorias básicas para estabelecer a classificação epidemiológica é a classe social, porque cada uma delas se depara, segundo sua inserção no aparelho produtivo, com de-terminadas condições de desenvolvimento das forças produtivas e com relações sociais específicas. Estas condições e relações determinam e modulam o conjunto de elementos da reprodução social, ou perfil reprodutivo, em meio do qual se estabelecem funcionamentos e probabilidades que podem implicar efeitos típicos de riscos e proteção em seus membros ou componentes. Quando os riscos predominam sobre as condições protetoras, atingindo um grande número de membros da classe, aparece um perfil patológico típico desse contingente ou, se é mais intenso, produz um padrão de mortalidade específico. Em contrapartida, se as condições protetoras predominam sobre os riscos, evidencia-se um perfil de saúde e, conseqüientemente, uma probabilidade de sobrevida.

O perfil produtivo de cada classe social é constituído pelas condições de trabalho e consumo ${ }^{2}$. As condições de trabalho incluem: o grau (quantidade média de gasto energético por unidade de tempo); a intensidade (nível de esforço e ritmo com que se efetua a jornada de trabalho); controle (relacão do trabalhador com o processo produtivo e sua possibilidade de controlá-lo) e as características laborativas (propriedades físicas, químicas ou biológicas).

As formas de consumo derivam da inserção de cada classe social na produção e das relações sociais que enfrenta, podendo ser classificadas $\mathrm{em}$ : consumo simples ou bio-social, relacionado ao conteúdo e quantidade dos bens básicos ou riscos decorrentes da alimentação, repouso, habitação, vestuário, recreação não estruturada e consumos físico-químicos ou biológicos obrigatórios (mercado, vias de comunicação, etc.) ou no 
espaço de gestăo (ideológica e política). O consumo ampliado (sóciocultural) envolve, ainda segundo os referidos autores, o acesso ou não aos bens sociais mais desenvolvidos, voltados às esferas da: recreação formativa, comunicação social, educação formal, serviços de saúde, transporte, organização política, dentre outras. As privações ou deformações no consumo ampliado produzem efeitos epidemiológicos específicos, configurando o perfil de morbimortalidade predominante nas classes sociais vinculadas áos processos produtivos mais desenvolvidos, inclusive os de suporte técnico-administrativo, especialmente nos grandes centros urbanos.

Em sintese, vale explicitar que efetivamente a teoria da determinação social do processo saúde-doença se constitui num avanço na medida em que vincula o biológico ao social. Entretanto, ao fazer uso de conceitos sociais, passa a se deparar com desafios que dizem respeito, tanto ao âmbito operacional quanto ao conceitual. Operacionalmente, delineiase a necessidade de criar instrumentos capazes de captar a dinâmica das relações sociais, ou seja, o movimento, a articulação e a explicitação das conseqüências decorrentes dessa determinação. Conceitualmente, cabe captar o espaço dos atoies sociais desse processo, passando a considerar dialeticamente essa relação. Assim, ganharia vida a concepção de que esse contexto, apesar de determinante não deixa de ser determinado pela ação intencional e organizada desses sujeitos. Por outro lado, também não é casual essa omissão. Historicamente, verifica-se que, salvo exceções, têm sido raros os movimentos em que se identifica a força resolutiva decorrente da intervenção consciente e organizada de grupos sociais na construção do processo histórico. Talvez nessa instância residam os principais dessfios da população, enquanto clientes e agentes da saúde, no caminho da superação da concepção e da prática ainda vigentes.

IDE, C.A.C. \& CHAVES, E.C. The problem of the determination of the health-illness process. Rev. Esc. Enf. USP, São Paulo, 24(1):163-167, Apr. 1990. process.

This research identifities the diferents possibilities to consience the health illness

UNITERMS: Health and disease. Social class.

\section{REFERENCIAS BIBLIOGRAFICAS}

1. AROUCA, A.T. Análise dos determinantes das condições de saúde da população brasileíra. In: GUIMARaes, R. Saúde e Medicina no Brasil: Contribuiçüo para um debato. 2. ed. Rlo de Janeiro, GRAAL, 1979 . p.147-54.

2. BREILH, J. \& GRANDA, E. Investigaça de saúde na sociedade: guía pedagógico sobre o novo enfoque do método epidemiológico. Săo Paulo, Instituto de Saúde, 1986. 213 p.

3. CONFERENCIA NACIONAL DE SAODE, 8., Brasilia, 1986. Anais. Brasilia, Centro de Documentação do Ministério da Saúde, 1987. 21p.

4. LAURELL, A.C. Ja politica de salud en los ochenta. Cuad. Pol., México, (23):89-97, mar. 1980.

5. LeavelL, H.R. \& Clark, E.G. Medivina Preventiva. São Paulo, McGruw-Hill, 1977. $744 \mathrm{p}$.

6. SINGER, $P$. et alii. Prevenir o curar: o controlo social através dos serviços de saúde. Rio de Janeiro. Forense Universitária, 1981. 166p.

Recebido em 01/08/89 